\title{
Differentiation of Different Nonmelanoma Skin Cancer Types Using OCT
}

\author{
Sebastian Batz Caroline Wahrlich Arash Alawi Martina Ulrich \\ Jürgen Lademann
}

Charité - Universitätsmedizin Berlin, corporate member of Freie Universität Berlin, Humboldt-Universität zu Berlin, and Berlin Institute of Health, Berlin, Germany; Department of Dermatology, Venerology and Allergology, Charité - Universitätsmedizin Berlin, Berlin, Germany

\section{Keywords}

Actinic keratosis - Basal cell carcinoma - Basalioma .

Superficial basal cell carcinoma $\cdot$ Morbus Bowen .

Squamous cell carcinoma - Optical coherence tomography

\begin{abstract}
Background: Early detection of various types of nonmelanoma skin cancer has been a challenge in dermatology. Noninvasive examination procedures such as optical coherence tomography (OCT) play an increasingly important role, besides the established gold standard of histological tissue sample analysis. OCT is a noninvasive, cross-sectional, realtime technique that allows conclusions to be drawn with regard to the presence of pathologies. Objective: The objective of this study was to investigate whether it is possible to distinguish between different types of nonmelanoma skin cancer using OCT or not. Methods: A study population of a total of 25 cases, comprising 5 cases, each, of 5 tumor entities (i.e., basal cell carcinoma, superficial basal cell carcinoma, actinic keratosis, squamous cell carcinoma, and Bowen disease) was examined. Relevant lesions were scanned both centrally and peripherally in the multislice mode. All OCT images were blinded, randomized, analyzed, and evaluated by 2 clinicians experienced in OCT. Results: This study
\end{abstract}

\section{KARGER}

() 2018 S. Karger AG, Basel

E-Mail karger@karger.com

www.karger.com/spp demonstrated that it is possible to determine correlations between various types of tumors and recurring tumor characteristics. Conclusion: This study showed that it is possible to distinguish between the different nonmelanoma skin cancers by using OCT, but further prospective studies have to be conducted to validate the sensitivity and specificity of the criteria.

(c) 2018 S. Karger AG, Basel

\section{Introduction}

A rapid increase in nonmelanoma skin cancer (NMSC) types has been observed in recent decades, especially affecting individuals in the age group 60 years and over. Moreover, studies have shown that this trend is more common in men than in women. Time-consuming and cost-intensive sampling and histopathological processing and dyeing of the samples is the gold standard in diagnosis of the various NMSC types to date. However, recently, noninvasive optical diagnostic methods have increasingly gained importance and show an increasing potential to complement the hitherto prevailing gold standard. For instance, procedures such as dermatoscopy, high-frequency ultrasound examination, and confocal microsco-

Prof. Dr. Dr.-Ing. Jürgen Lademan

Department of Dermatology, Venerology and Allergology

Charité - Universitätsmedizin Berlin

Charitéplatz 1, DE-10117 Berlin (Germany)

E-Mail juergen.lademann@ charite.de 
py have already become established in the early detection of NMSC types [1-3]. Another equally promising procedure that is increasingly gaining importance is optical coherence tomography (OCT). Like the above-mentioned procedures, OCT is an easily applied, noninvasive, realtime technique that is based on low-coherence interferometry [4]. OCT was first practically described by Huang et al. [5] in 1991. Since then, it has undergone a continuous process of improvement and advancement along with an extended field of application.

Thus, OCT has become a firmly established examination tool in the special fields of dermatology and ophthalmology [6-8], and it has generally been tested and used in all medical fields. For instance, OCT is already used in gastroenterology to detect malignant lesions in the gastrointestinal tract as well as possible responses to the resulting cancer therapy [9-11]. Moreover, application possibilities of OCT regarding breast cancer have been investigated in gynecology $[12,13]$. The application of OCT in the field of neurology is also highly interesting. In neurology, OCT can be used to observe the effects of intracranial hypertension and allows detection of the activity of demyelinating diseases even before neurological symptoms become apparent $[14,15]$.

Dermatology is another special field where OCT and its application have been under investigation for a long time. OCT itself and the requirements of OCT have continuously changed from the first examinations of human skin in 1997 to studies dealing with more complex topics such as the applicability of OCT in wound healing or the definition of surgical resection limits $[4,16,17]$. However, the greatest and most sophisticated challenge is to investigate the applicability of OCT in NMSC diagnosis. Several studies have already been dedicated to the topic of creating standard detection criteria for the different NMSC types $[2,18-23]$. Such standard criteria have successfully been defined for actinic keratosis (AK) as well as basal cell carcinoma (BCC), but they have turned out to be rather difficult to determine for the other tumor entities. In this study, we aimed to show correlations between detection criteria and the different NMSC types by means of OCT.

\section{Materials and Methods}

\section{Participants}

A total of 35 patients (16 males and 19 females) with a large variety of nonmelanoma tumor entities and lesions were examined using OCT in the period between June 2012 and February 2013, and the results of those examinations were acquired for our study. All of the participants were informed in detail about their inclusion into this study and the general conditions of this study prior to the examination and gave their written consent. This study was approved by the ethics committee of the Charité - Universitätsmedizin Berlin (EA1/061/09). All scientific research and examinations were performed in compliance with the principles of the Declaration of Helsinki. At the time of the measurements, all participating patients had already been scheduled for verification by biopsy or surgical excision of their lesion. All examinations, measurements, and histopathological evaluations were performed at the Department of Dermatology, Venerology and Allergology of the Charité - Universitätsmedizin Berlin.

After the initial evaluation of the histopathological results and quality assessment of the OCT-specific images, the patient population of this study was reduced by 10 cases because images did not fulfill the quality criteria or histological results of the sample biopsies did not correspond to the tumor entities included in this study. Hence, 25 patients (15 males and 10 females) with a mean age of 69 years (range $32-88$ ) were finally included and evaluated in this study. All examined lesions of the participants in this study were scanned both centrally and peripherally in the OCT multislice mode. Unaffected skin on the contralateral side was also scanned for reference.

\section{OCT Device}

OCT is a noninvasive, cross-sectional, real-time technique based on Michelson interferometry that is used to examine all kinds of benign and malignant skin diseases [18]. The lateral optical resolution is approximately $7.5 \mu \mathrm{m}$ and the axial resolution is approximately $<10 \mu \mathrm{m}$. The scan covers an area of $6 \times 6 \mathrm{~mm}^{2}$ at a maximum depth of $2 \mathrm{~mm}$. Moreover, the examiner can choose between various acquisition modes such as, for example, the free run mode and the multislice mode. In the free run mode, the scan is only performed along the $x$ axis, thus allowing free movability of the scan head. This is of special advantage if several regions are searched for potential lesions. By contrast, in the multislice mode, an entire series of images is acquired. Each area covered with this mode measures $6 \times 6 \mathrm{~mm}^{2}$ and represents 1 image. The individual images are scanned at increments of $0.1 \mathrm{~mm}$ along the $y$ axis [4]. This mode is primarily selected to visualize the transition between tumor-free skin and tumor. All examinations were performed with the OCT scanner type Vivosight of Michelson Diagnostics (Kent, $\mathrm{UK})$. All measurements regarding the various tumor entities were exclusively performed in the multislice mode.

\section{Imaging Procedure}

The actual examination was performed by means of a multibeam OCT scanner after the participants had given their written informed consent. The affected skin regions were not specifically prepared for the measurements. Very hairy areas (e.g., the back part of the head, the arms, and the abdomen) were shaved to prevent potential interference and achieve an undisturbed deep penetration. The patients were asked to lie down flat on their back on the examination table throughout the procedure. The examination was performed using standard OCT settings. Thus, a high quality of measurements was achieved and a high reproducibility was ensured. Each patient underwent 3 measurements in the multislice mode, each consisting of a series of 60 consecutive individual frames. The first measurement was always performed peripherally at the transition from unaffected skin towards the lesion. Then, the center of the lesion was scanned to cover the different characteristics within the lesion. Finally, a ref- 


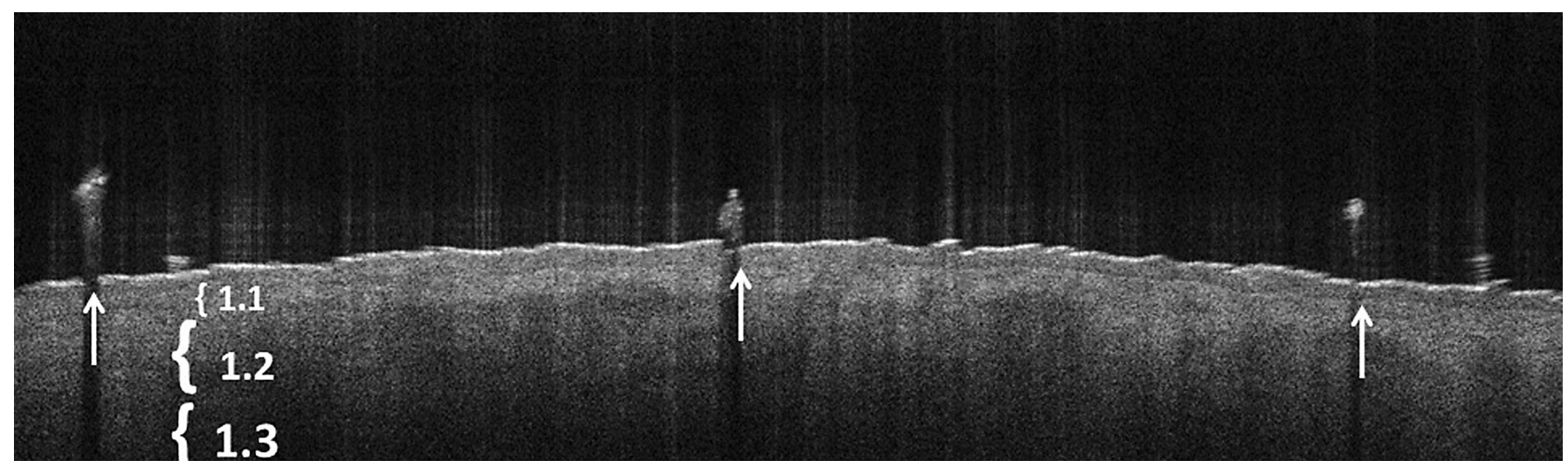

Fig. 1. Patient with medically normal skin. Different sections display the layers of normal skin (i.e., 1.1, epidermis; 1.2 , dermis; and 1.3, subcutis). The arrows indicate hair follicles.

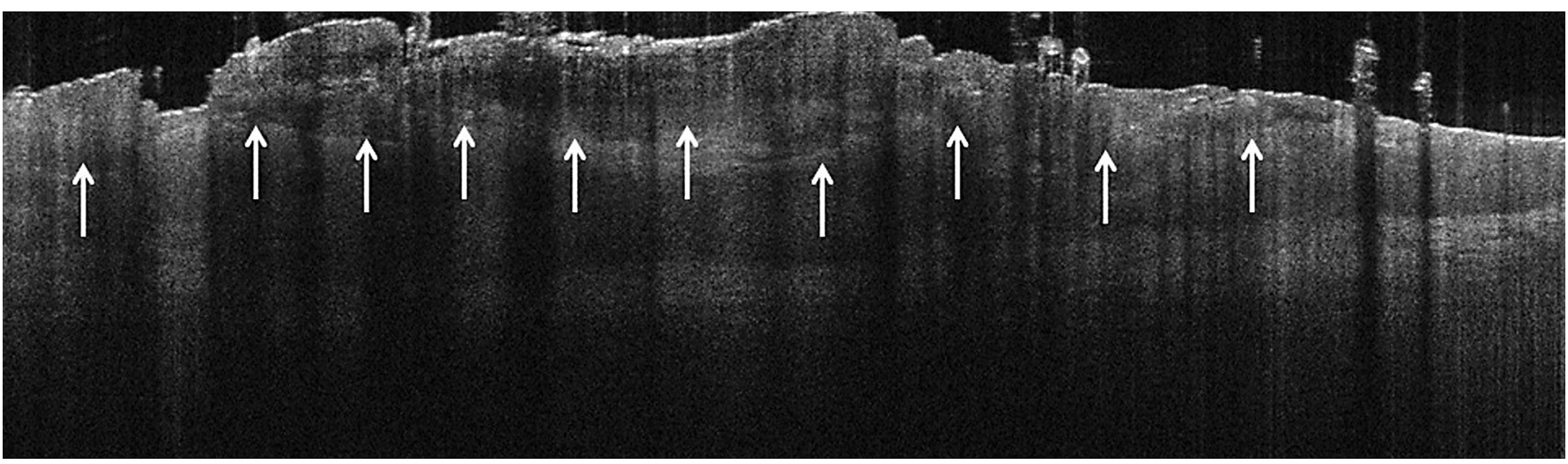

Fig. 2. Patient with histologically verified squamous cell carcinoma and well-defined continuous parakeratosis. The arrows indicate thickened/infiltrated skin layers.

erence scan of healthy skin on the contralateral side of the body was performed. This reference scan allowed differentiation between the characteristics of healthy and tumorous skin because healthy skin is exposed to all kinds of noxae over the years such as light and chemical substances as well as plain skin aging and, therefore, may also show pathologies. After the examination, all of the participants received their specific, previously planned therapy.

\section{Statistics}

Microsoft Office Excel 2007 was used to compile the data for the statistical analysis. The statistical data analysis was performed by means of SPSS 22 (SPSS Inc., Chicago, IL, USA). The normality of the age-specific distribution of the patient population was verified and confirmed beforehand with the Kolmogorov-Smirnov test. The actual statistical analysis of the 5 individual tumor criteria in relation to the 5 relevant tumor entities was performed by means of the $\mathrm{X}^{2}$ test. The absolute presence of various criteria in the individual tumor entities was determined based on purely descriptive analysis. After the statistical analysis, all results with a positive or negative Pearson $\phi$ coefficient and a $p$ value $<0.05$ were rated as significant. Moreover, trends were determined within the range $0.005<p \leq 0.1$.

\section{Development of Detection Criteria}

In view of the fact that the incidence of NMSC types has continuously increased in the past decades, several studies have already been performed to investigate the applicability of OCT and early detection of these diseases by means of OCT and create standard detection criteria [1, 2, 18-22, 24, 25]. In the so-called "Berlin Score," for instance, the focus was primarily placed on recurring OCT characteristics of BCC and their subtypes to investigate a possible correlation and its practical application to, and usefulness in, clinical routine [18]. In this study, similar characteristics were used as in previous studies [18] with regard to 5 different tumor entities, i.e., BCC, sBCC, AK, Bowen disease, and squamous cell carcinoma (SCC), to investigate any existing correlations. All characteristics were established based on clinical OCT experience and in close cooperation with dermatologists, students, and histopathologists. Other criteria such as parakeratosis, acanthosis, and occurrence of hyperreflective nests were analyzed besides the criteria established in the Berlin Score (e.g., noncompressible dark borders, ovoid structures, and hyporeflective nests) [18]. Similar to the Berlin Score all subtypes of BCC were included (e.g., nodular, micronodular, cystic BCC, etc.). A total of 25 cases corresponding to 5 cases 


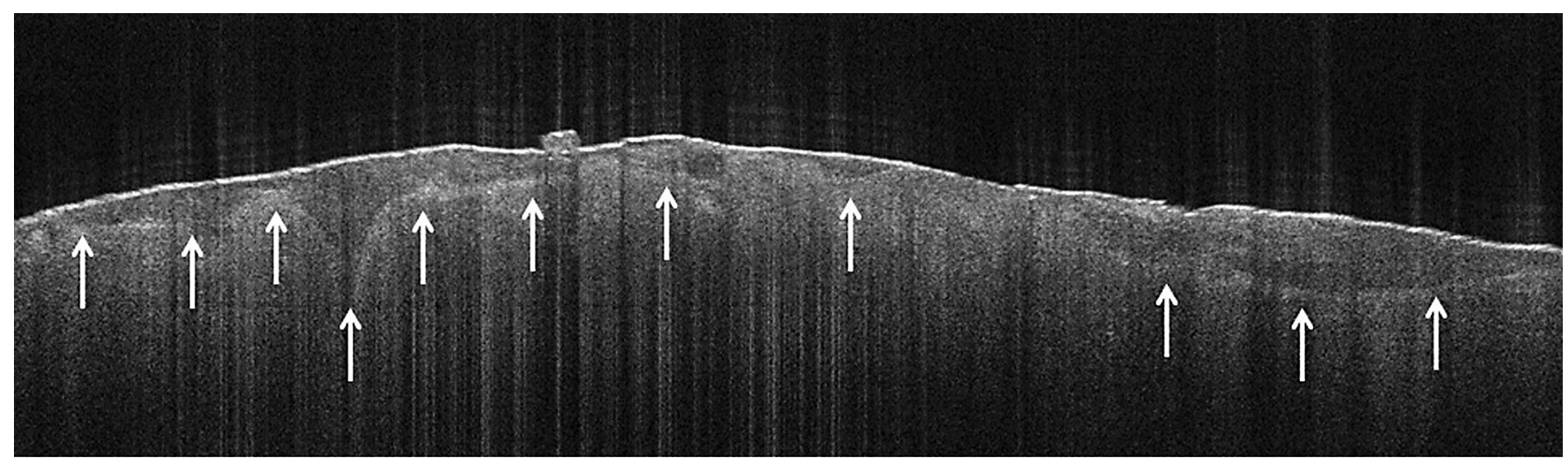

Fig. 3. Patient with histologically verified Bowen disease and a thickened spinous layer (marked by the arrows).

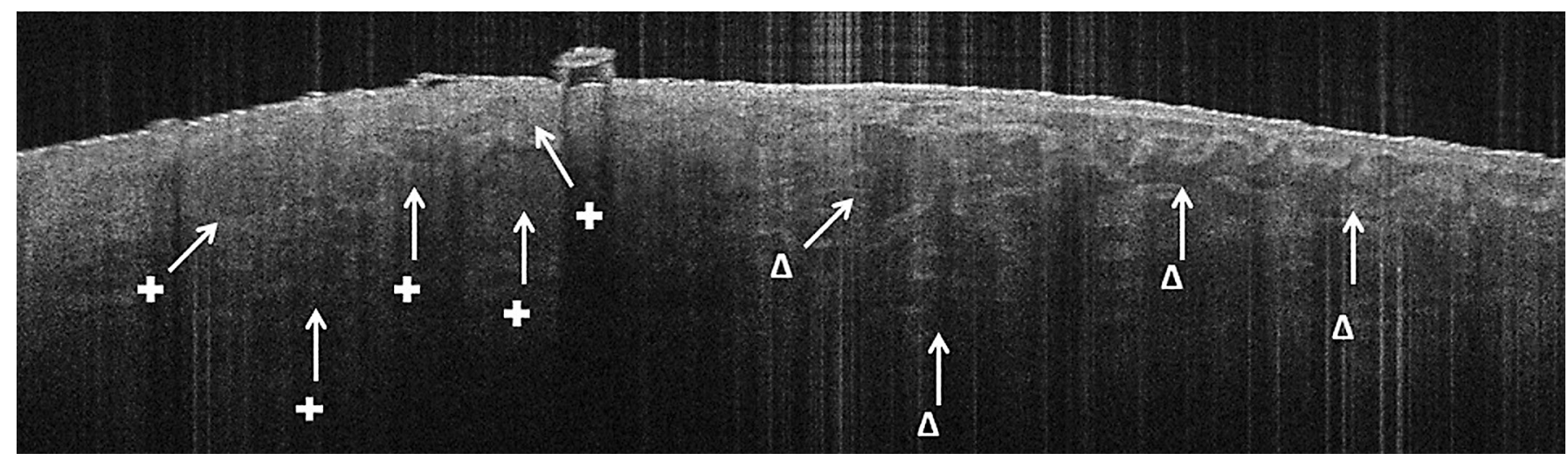

Fig. 4. Patient with histologically verified basal cell carcinoma and visible oviod structures $(+)$ and hyporefelctive nests $(\Delta)$.

per tumor entity were blinded, randomized, and passed on to a team of 2 analysts experienced in OCT (a dermatologist and a human medicine student) for evaluation. A purely descriptive analysis dealt only with the presence or absence of predefined criteria, where the score 0 was assigned to absence and 1 to presence. After the evaluation was completed, all OCT images were assigned to the relevant patient data and histologies (Fig. 1-8; Table 1).

\section{Results}

The results were evaluated based on a population of 25 patients (15 males and 10 females). The ensuing Kolmogorov-Smirnov test showed normality of the age-specific distribution. The mean patient age was 69 years. The $\mathrm{X}^{2}$ test performed in relation to the gender-specific occurrence of tumor characteristics in the individual entities did not reveal any significant difference between the sexes.
The followings results were obtained for the individual characteristics in relation to the different tumor entities.

The occurrence of the specific characteristic parakeratosis was negatively associated with the tumor entity BCC $(\phi=-0.579, p=0.004)$.

BCC was also negatively associated with the characteristic generalized acanthosis $(\phi=-0.750, p<0.001)$.

The results obtained for focal acanthosis with the tumor entity sBCC were different; a significantly positive association was found $(\phi=0.500, p=0.012)$.

The characteristic multifocal acanthosis showed a significantly positive correlation with SCC $(\phi=0.408, p=$ $0.041)$ and Bowen disease $(\phi=0.408, p=0.041)$. By contrast, a negative significance was found regarding $\mathrm{BCC}$ $(\phi=-0.612, p=0.002)$ and $\operatorname{sBCC}(\phi=-0.408, p=0.04)$.

Trends related to the characteristics were also shown with the $\mathrm{X}^{2}$ test. For instance, a negative trend was found 


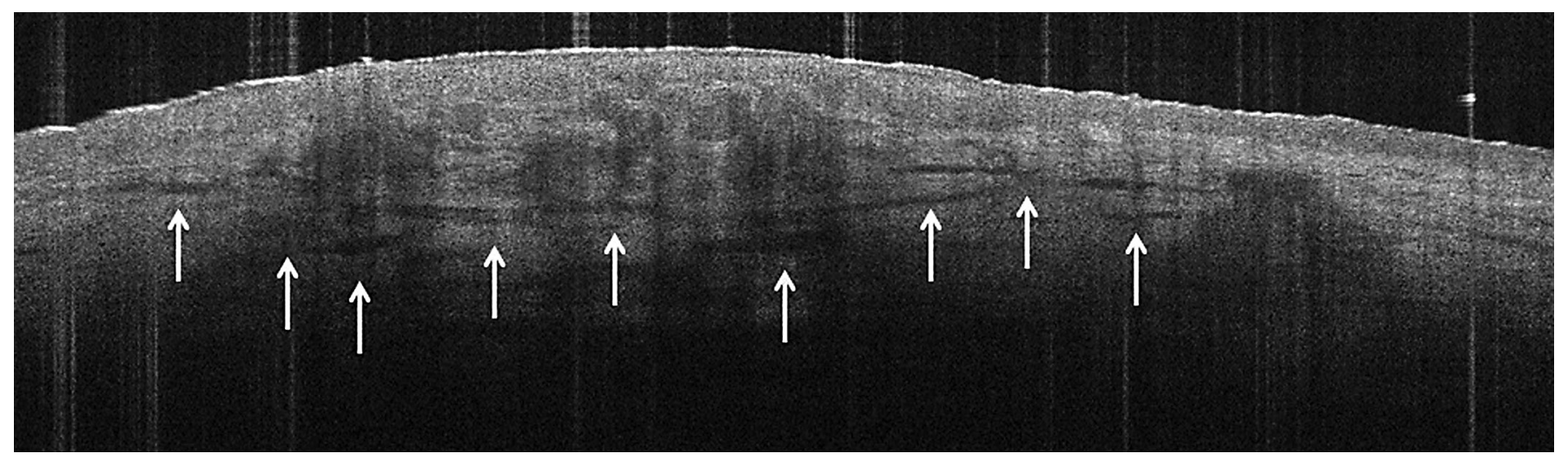

Fig. 5. Another patient with histologically verified basal cell carcinoma and a noncompressible dark border beneath the tumor (indicated by the arrows).

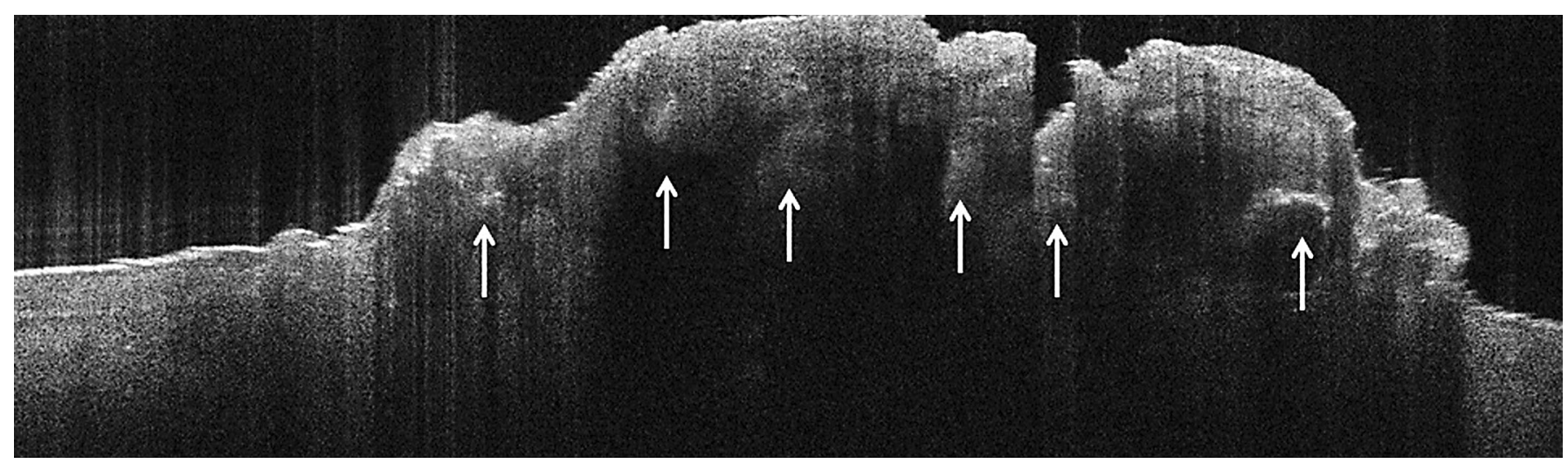

Fig. 6. Patient with histologically verified squamous cell carcinoma and distinct hyperreflective nests (indicated by the arrows).

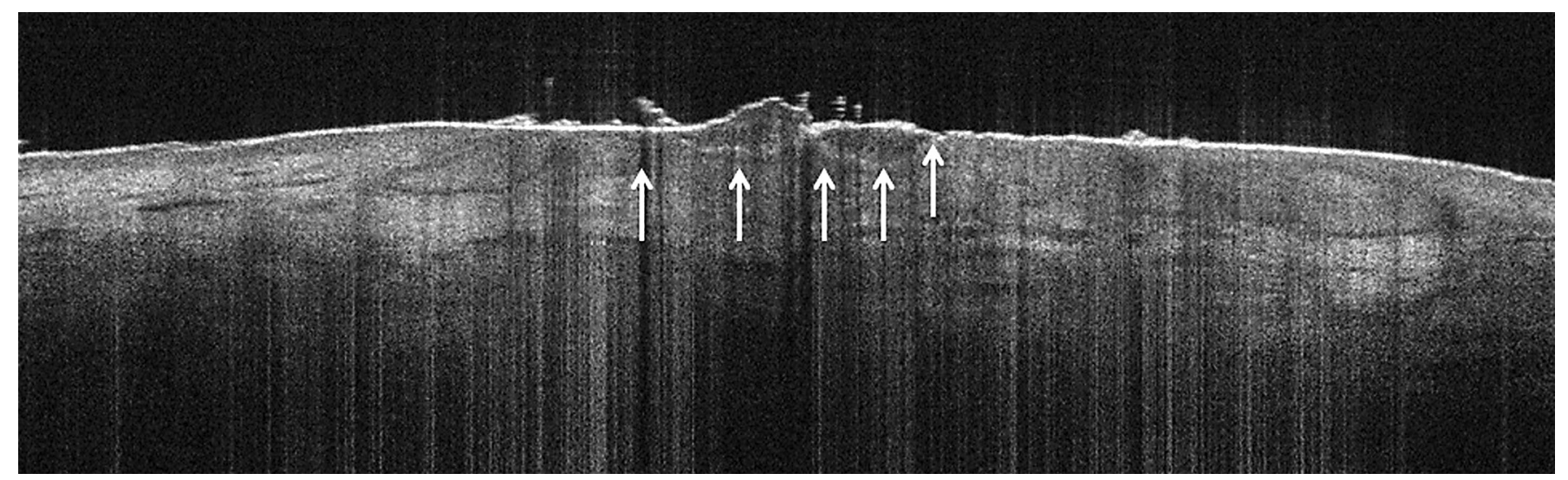

Fig. 7. Patient with histological verified superficial basal cell carcinoma. The arrows indicate tumor starting from the epidermis with minor hyperkeratosis. 


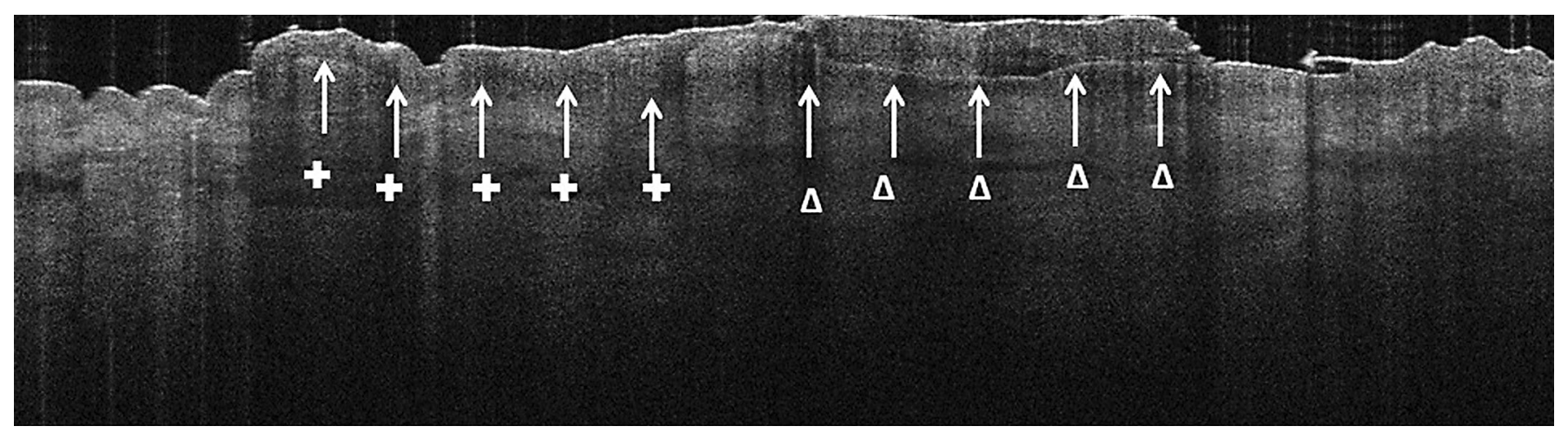

Fig. 8. Patient with histological verified actinic keratosis. The arrows indicate parakeratosis and hyperkeratosis of the upper skin layers $(+)$ and acanthosis of the epidermis $(\Delta)$.

Table 1. Association of the established detection criteria with the different skin layers

\begin{tabular}{|c|c|c|c|}
\hline & Epidermis & Dermis & Subcutis \\
\hline Parakeratosis & $\begin{array}{l}\text { Cornification disorder starting } \\
\text { at the stratum corneum, visible } \\
\text { as a thickened cell bulk }\end{array}$ & & \\
\hline $\begin{array}{l}\text { Acanthosis } \\
\text { (focal/multifocal) }\end{array}$ & $\begin{array}{l}\text { Broadened stratum spinosum } \\
\text { with acanthoid branches into } \\
\text { deeper skin layers, focal or } \\
\text { multifocal }\end{array}$ & & \\
\hline $\begin{array}{l}\text { Hyporeflective } \\
\text { nests }\end{array}$ & & $\begin{array}{l}\text { Dark an } \\
\text { mostly l } \\
\text { dermis; } \\
\text { stroma }\end{array}$ & $\begin{array}{l}\text { mogeneous areas } \\
\text { in the upper } \\
\text { ates to variable } \\
\text { l aggregates }\end{array}$ \\
\hline $\begin{array}{l}\text { Hyperreflective } \\
\text { nests }\end{array}$ & $\begin{array}{l}\text { Homogeneous ovoid structures, } \\
\text { surrounded by stroma with } \\
\text { an exclusively hyperreflective } \\
\text { character }\end{array}$ & & \\
\hline $\begin{array}{l}\text { Noncompressible } \\
\text { dark border }\end{array}$ & & & $\begin{array}{l}\text { Localized from the dermis } \\
\text { to subcutis under tumor nests; due } \\
\text { to its noncompressible character } \\
\text { there are no blood vessels present }\end{array}$ \\
\hline
\end{tabular}

for the criterion hyporeflective nests in relation to the tumor entities Bowen disease $(\phi=-0.343, p=0.086)$ and AK $(\phi=-0.343, p=0.086)$. By contrast, the presence of ovoid, hyporeflective nests was significantly positively correlated with the tumor entity BCC $(\phi=0.729, p<$ 0.001).

The criterion hyperreflective nests showed a significantly positive association with SCC $(\phi=0.590, p=0.003)$.

Noncompressible dark border, the last recurring criterion analyzed, was significantly positively correlated with $\operatorname{sBCC}(\phi=0.458, p=0.022)$ and $\operatorname{BCC}(\phi=0.667, p=$
$0.001)$ and showed negative trends regarding the other 3 tumor entities, i.e., SCC $(\phi=-0.375, p=0.061)$, Bowen disease $(\phi=-0.375, p=0.061)$, and AK $(\phi=0.375, p=$ 0.061 ; Table 2).

\section{Discussion}

OCT allows unambiguous differentiation between benign and malignant skin lesions already at an early stage. However, distinguishing between individual tumor enti- 
Table 2. Overview of the significant results of the criteria with reference to the different tumor entities

\begin{tabular}{|c|c|c|c|c|c|c|}
\hline $\mathrm{AK}$ & & & & $(-)$ & & - \\
\hline BCC & - & - & & $(+)$ & & \\
\hline sBCC & & - & + & & & + \\
\hline Bowen disease & & + & & $(-)$ & & - \\
\hline
\end{tabular}

AK, actinic keratosis; BCC, basal cell carcinoma; sBCC, superficial basal cell carcinoma; SCC, squamous cell carcinoma; +, positive significance; - , negative significance; $(-)$, negative trend; $(+)$, positive trend.

ties is still problematic $[18,24,26,27]$. In this purely descriptive study, it was shown that almost all tumor entities have recurring characteristics that might allow differentiation by means of OCT in the future. Correlation and discrimination of the individual tumor entities based on signal intensity and layer thickness as described in former studies were not included in this study [28].

The so-called trends are also a factor that should not be neglected. They might play a significant role in larger study populations with greater numbers of cases and also possibly contribute to improved differentiation between the individual types of tumors.

However, there are also disadvantages with regard to OCT and its evaluability in this study. For instance, the applicability of OCT is limited to body regions where an adequate contact area between the scan unit and the skin surface is ensured. This makes OCT more difficult to use on acra or bony structures of the body. Moreover, the examiner's experience in handling OCT and his/her analytical skills influence the achieved image quality and the results of the evaluation of the obtained image material and present a source of error that should not be underestimated. It is mandatory in the evaluation of OCT images to include healthy skin of the contralateral side for reference because even healthy skin is exposed to natural aging, noxae, and the sun, thus causing pathologies and leading to misinterpretation.

Time-consuming and cost-intensive sampling, histopathological processing, and evaluation of the samples is still the gold standard for the early detection of the various NMSC types to date. To date, it is not yet possible to use OCT as the only tool in early detection of NMSC types because of technical limitations. However, like other noninvasive real-time techniques, OCT promises the possibility of a fast, easy, cost-effective, and painless means to replace the existing standard in the future. This as- sumption is especially encouraged by the latest developments such as HD-OCT (high-definition OCT) and SVOCT (speckle-variance OCT) as well as D-OCT (dynamic OCT) [29-34]. D-OCT, a naval angiographic variant of OCT, for example, may aid in distinguishing between the different tumor entities because of its particular vascular morphology. This was already demonstrated using the example of AK, Bowen disease, and SCC [34]. In the context of further studies, the already established differentiation criteria could be complemented.

\section{Acknowledgement}

The authors would like to thank all of the participants of this work, especially Michelson Diagnostics, for driving the results of this work with their assistance and critical comments. The authors would specifically like to thank Dr. Roland Sauer who always helped with words and deeds.

\section{Statement of Ethics}

The study was approved by the Ethic Commission of the Charité-Universitätsmedizin Berlin (EA1/061/09). All patients provided written informed consent. The study was conducted according to the guidelines of Good Clinical Practice.

\section{Disclosure Statement}

The authors have no conflict of interests to declare. 


\section{References}

-1 Samarasinghe V, Madan V: Nonmelanoma skin cancer. J Cutan Aesthet Surg 2012;5:310.

-2 Wassef C, Rao BK: Uses of non-invasive imaging in the diagnosis of skin cancer: an overview of the currently available modalities. Int J Dermatol 2013;52:1481-1489.

-3 Krutmann J, Berking C, Berneburg M, Diepgen TL, Dirschka T, Szeimies M: New strategies in the prevention of actinic keratosis: a critical review. Skin Pharmacol Physiol 2015; 28:281-289.

-4 Alawi SA, Kuck M, Wahrlich C, Batz S, McKenzie G, Fluhr JW, Lademann J, Ulrich M: Optical coherence tomography for presurgical margin assessment of non-melanoma skin cancer - a practical approach. Exp Dermatol 2013;22:547-551

5 Huang D, Swanson EA, Lin CP, Schuman JS, Stinson WG, Chang W, Hee MR, Flotte T, Gregory K, Puliafito CA, Fujimoto JG: Optical coherence tomography. Science 1991;254: 1178-1181.

-6 Swanson EA, Izatt JA, Hee MR, Huang D, Lin CP, Schuman JS, Puliafito CA, Fujimoto JG: In-vivo retinal imaging by optical coherence tomography. Opt Lett 1993;18:1864-1866.

$>7$ Lasave AF: Current interpretation of optical coherence tomography in the posterior pole. Arch Soc Esp Oftalmol 2016;91:3-9.

>8 Siedlecki D, Kowalik W, Kasprzak H: Optical coherence tomography as a tool for ocular dynamics estimation. Biomed Res Int 2015; 2015:293693.

$>9$ Kirtane TS, Wagh MS: Endoscopic optical coherence tomography (OCT): advances in gastrointestinal imaging. Gastroenterol Res Pract 2014;2014:376367.

-10 Adler DC, Zhou C, Tsai TH, Lee HC, Becker L, Schmitt JM, Huang Q, Fujimoto JG, Mashimo H: Three-dimensional optical coherence tomography of Barrett's esophagus and buried glands beneath neosquamous epithelium following radiofrequency ablation. Endoscopy 2009;41:773-776.

$>11$ Xiong H, Guo Z, Zeng C, Wang L, He Y, Liu $\mathrm{S}$ : Application of hyperosmotic agent to determine gastric cancer with optical coherence tomography ex vivo in mice. J Biomed Opt 2009; 14:024029.

$>12$ South FA, Chaney EJ, Marjanovic M, Adie SG, Boppart SA: Differentiation of ex vivo human breast tissue using polarization-sensitive optical coherence tomography. Biomed Opt Exp 2014;5:3417-3426.

-13 Grieve K, Mouslim K, Assayag O, Dalimier E, Harms F, Bruhat A, Boccara C, Antoine M: Assessment of sentinel node biopsies with full-field optical coherence tomography. Technol Cancer Res Treat 2016;15:266-274.
14 Nolan RC, Narayana K, Galetta SL, Balcer LJ: Optical coherence tomography for the neurologist. Semin Neurol 2015;35:564-577.

15 Knier B, Berthele A, Buck D, Schmidt P, Zimmer C, Muhlau M, Hemmer B, Korn T: Optical coherence tomography indicates disease activity prior to clinical onset of central nervous system demyelination. Mult Scler 2016; 22:893-900.

16 Welzel J, Lankenau E, Birngruber R, Engelhardt R: Optical coherence tomography of the human skin. J Am Acad Dermatol 1997;37: 958-963.

17 Kuck M, Strese H, Alawi SA, Meinke MC, Fluhr JW, Burbach GJ, Krah M, Sterry W, Lademann J: Evaluation of optical coherence tomography as a non-invasive diagnostic tool in cutaneous wound healing. Skin Res Technol 2014;20:1-7.

18 Wahrlich C, Alawi SA, Batz S, Fluhr JW, Lademann J, Ulrich M: Assessment of a scoring system for basal cell carcinoma with multi-beam optical coherence tomography. J Eur Acad Dermatol Venereol 2015;29:15621569.

19 Boone MA, Norrenberg S, Jemec GB, Del Marmol V: Imaging of basal cell carcinoma by high-definition optical coherence tomography: histomorphological correlation - a pilot study. Br J Dermatol 2012;167:856-864.

20 Boone MA, Norrenberg S, Jemec GB, Del Marmol V: Imaging actinic keratosis by highdefinition optical coherence tomography: histomorphologic correlation - a pilot study. Exp Dermatol 2013;22:93-97.

21 Hussain AA, Themstrup L, Jemec GB: Optical coherence tomography in the diagnosis of basal cell carcinoma. Arch Dermatol Res 2015;307:1-10.

22 Mogensen M, Thrane L, Jorgensen TM, Andersen PE, Jemec GB: Oct imaging of skin cancer and other dermatological diseases. J Biophotonics 2009;2:442-451.

23 Coleman AJ, Richardson TJ, Orchard G, Uddin A, Choi MJ, Lacy KE: Histological correlates of optical coherence tomography in nonmelanoma skin cancer. Skin Res Technol 2013;19:10-19.

24 Mogensen M, Joergensen TM, Nurnberg BM, Morsy HA, Thomsen JB, Thrane L, Jemec GB: Assessment of optical coherence tomography imaging in the diagnosis of non-melanoma skin cancer and benign lesions versus normal skin: observer-blinded evaluation by dermatologists and pathologists. Dermatol Surg 2009;35:965-972.
25 Olsen J, Themstrup L, De Carvalho N, Mogensen M, Pellacani G, Jemec GB: Diagnostic accuracy of optical coherence tomography in actinic keratosis and basal cell carcinoma. Photodiagnosis Photodyn Ther 2016;16:4449.

26 Schuh S, Kaestle R, Sattler E, Welzel J: Comparison of different optical coherence tomography devices for diagnosis of non-melanoma skin cancer. Skin Res Technol 2016;22:395405 .

27 Themstrup L, Banzhaf CA, Mogensen M, Jemec GB: Optical coherence tomography imaging of non-melanoma skin cancer undergoing photodynamic therapy reveals subclinical residual lesions. Photodiagnosis Photodyn Ther 2014;11:7-12.

28 Schuh S, Kaestle R, Sattler EC, Welzel J: Optical coherence tomography of actinic keratoses and basal cell carcinomas - differentiation by quantification of signal intensity and layer thickness. J Eur Acad Dermatol Venereol 2016;30:1321-1326.

29 Marneffe A, Suppa M, Miyamoto M, Del Marmol V, Boone M: Validation of a diagnostic algorithm for the discrimination of actinic keratosis from normal skin and squamous cell carcinoma by means of high-definition optical coherence tomography. Exp Dermatol 2016;25:684-687.

30 Cao TT, Tey HL: High-definition optical coherence tomography - an aid to clinical practice and research in dermatology. J Dtsch Dermatol Ges 2015;13:886-890.

-31 De Carvalho N, Ciardo S, Cesinaro AM, Jemec GBE, Ulrich M, Welzel J, Holmes J, Pellacani G: In vivo micro-angiography by means of speckle-variance optical coherence tomography (SV-OCT) is able to detect microscopic vascular changes in naevus to melanoma transition. J Eur Acad Dermatol Venereol 2016;30:E67-E68.

-32 Marvdashti T, Duan L, Aasi SZ, Tang JY, Bowden AKE: Classification of basal cell carcinoma in human skin using machine learning and quantitative features captured by polarization sensitive optical coherence tomography. Biomed Opt Exp 2016;7:3721-3735.

33 Boone M, Suppa M, Miyamoto M, Marneffe A, Jemec G, Del Marmol V: In vivo assessment of optical properties of basal cell carcinoma and differentiation of bcc subtypes by high-definition optical coherence tomography. Biomed Opt Exp 2016;7:2269-2284.

>34 Themstrup L, Pellacani G, Welzel J, Holmes J, Jemec GBE, Ulrich M: In vivo microvascular imaging of cutaneous actinic keratosis, Bowen's disease and squamous cell carcinoma using dynamic optical coherence tomography. J Eur Acad Dermatol Venereol 2017;31:16551662. 